\title{
The effects of the semirecumbent position on hemodynamic status in patients on invasive mechanical ventilation: prospective randomized multivariable analysis
}

Ivan Göcze ${ }^{1 *}$, Felix Strenge ${ }^{2}$, Florian Zeman ${ }^{3}$, Marcus Creutzenberg ${ }^{4}$, Bernhard M Graf $^{4}$, Hans J Schlitt $^{1}$ and Thomas Bein ${ }^{4}$

\begin{abstract}
Introduction: Adopting the $45^{\circ}$ semirecumbent position in mechanically ventilated critically ill patients is recommended, as it has been shown to reduce the incidence of ventilator-associated pneumonia. Although the benefits to the respiratory system are clear, it is not known whether elevating the head of the bed results in hemodynamic instability. We examined the effect of head of bed elevation (HBE) on hemodynamic status and investigated the factors that influence mean arterial pressure (MAP) and central venous oxygen saturation (ScvO2) when patients were positioned at $0^{\circ}, 30^{\circ}$, and $45^{\circ}$.

Methods: Two hundred hemodynamically stable adults on invasive mechanical ventilation admitted to a multidisciplinary surgical intensive care unit were recruited. Patients' characteristics included catecholamine and sedative doses, the original angle of head of bed elevation (HBE), the level of positive end expiratory pressure (PEEP), duration and mode of mechanical ventilation. A sequence of HBE positions $\left(0^{\circ}, 30^{\circ}\right.$, and $\left.45^{\circ}\right)$ was adopted in random order, and MAP and ScvO2 were measured at each position. Patients acted as their own controls. The influence of degree of HBE and of the covariables on MAP and ScvO2 was analyzed by using liner mixed models. Additionally, uni- and multivariable logistic regression models were used to indentify risk factors for hypotension during $\mathrm{HBE}$, defined as MAP $<65 \mathrm{mmHg}$.
\end{abstract}

Results: Changing HBE from supine to $45^{\circ}$ caused significant reductions in MAP (from $83.8 \mathrm{mmHg}$ to $71.1 \mathrm{mmHg}$, $P<0.001)$ and ScvO2 (76.1\% to $74.3 \%, P<0.001)$. Multivariable modeling revealed that mode and duration of mechanical ventilation, the norepinephrine dose, and HBE had statistically significant influences. Pressure-controlled ventilation was the most influential risk factor for hypotension when HBE was $45^{\circ}$ (odds ratio (OR) 2.33, 95\% confidence interval $(\mathrm{Cl}), 1.23$ to $4.76, P=0.017)$.

Conclusions: HBE to the $45^{\circ}$ position is associated with significant decreases in MAP and ScvO2 in mechanically ventilated patients. Pressure-controlled ventilation, higher simplified acute physiology (SAPS II) score, sedation, high catecholamine, and PEEP requirements were identified as independent risk factors for hypotension after backrest elevation. Patients at risk may need positioning at $20^{\circ}$ to $30^{\circ}$ to overcome the negative effects of $\mathrm{HBE}$, especially in the early phase of intensive care unit admission.

\footnotetext{
* Correspondence: ivan.goecze@ukr.de

'Department of Surgery, University Medical Centre Regensburg, Franz-Josef-

Strauss-Allee 11, D-93053 Regensburg, Germany

Full list of author information is available at the end of the article
} 


\section{Introduction}

The semirecumbent position is an upright positioning of the head and torso at an angle of $45^{\circ}$. The effects of adopting the semirecumbent position in critically ill patients have been extensively investigated as a potential means of preventing ventilator-associated pneumonia (VAP). VAP develops in $5 \%$ to $25 \%$ of ventilated patients and it is associated with prolonged duration of mechanical ventilation, hospital stay, and increased morbidity and mortality [1-3].

Reflux of gastric contents and subsequent microaspiration of bacterial contaminated oropharyngeal fluids play crucial role in development of VAP [4]. Use of histamine-2 receptor blockers or proton pump inhibitors (PPI) increases gastric $\mathrm{pH}$ and enhances colonization with pathogens. The combination of a nasogastric feeding tube and the supine position facilitates gastroesophageal reflux and increases the volume of oropharyngeal fluids significantly. The incidence of VAP is independently associated with a supine $\left(0^{\circ}\right)$ head of bed position during the first $24 \mathrm{~h}$ of mechanical ventilation [5]. Nursing patients in the semirecumbent position substantially decreases the aspiration of gastric contents, and a randomized trial has confirmed that this significantly reduces the incidence of VAP [6-8].

Despite being widely adopted, there is still some uncertainty about the routine use of the upright position. Control groups in trials investigating head of bed elevation (HBE) were nursed supine at $0^{\circ}$, which does not reflect current practice. It is also not known whether elevating the head of the bed to $45^{\circ}$ may cause hemodynamic instability [9].

We examined the influence of HBE on hemodynamic status in patients on invasive mechanical ventilation. After randomization to one of six possible sequences of positioning we assessed hemodynamic parameters and central venous oxygen saturation in each position and also examined the variables that might be independent predictors of hemodynamic changes.

\section{Methods}

\section{Patients}

Two hundred patients were recruited in the multidisciplinary surgical intensive care unit (ICU) of a tertiary care university hospital. The study was approved by the local Institutional Review Board (Ethikkommision Universität Regensburg, no 10-101-0280). The written consent of unresponsive patients was obtained either from them after they regained responsiveness or from their next of kin. All hemodynamically stable, mechanically ventilated patients over the age of 18 years with a central venous catheter situated in the superior vena cava on the ICU were eligible for inclusion in the study. Hemodynamic stability was defined as a stable mean arterial pressure by constant inotropic support without additional fluid administration. Patients with acute cardiovascular instability, or those with pump-driven circulatory or respiratory support, were excluded from the study. Also excluded were all patients in whom the supine position is contraindicated (for example, patients with traumatic brain injury), or those who were immobilized due to spinal injuries or unstable pelvic fractures.

The amount of positive inotropic support, length of mechanical ventilation, ventilation mode, or length of ICU stay did not influence inclusion or exclusion from the study. We chose 15 disease categories to describe the admission diagnoses. Severity of the illness was recorded using the Simplified Acute Physiology Score (SAPS II), which expresses the probability of mortality based on 12 variables including a combination of physiological, laboratory, and clinical data [10]. Hemodynamic parameters and central venous oxygen saturation were recorded in each position.

\section{Randomization}

Sequences of six possible combinations of three positions $\left(0^{\circ}, 30^{\circ}\right.$, and $\left.45^{\circ}\right)$ were determined: $0^{\circ}, 30^{\circ}$, then $45^{\circ} ; 0^{\circ}, 45^{\circ}$, then $30^{\circ} ; 30^{\circ}, 0^{\circ}$, then $45^{\circ} ; 30^{\circ}, 45^{\circ}$, then $0^{\circ}$; $45^{\circ}, 0^{\circ}$, then $30^{\circ} ; 45^{\circ}, 30^{\circ}$, then $0^{\circ}$. Each combination was randomly assigned a number from 1 to 200 . An independent institution created the random order (randomlist) and randomization was made in blocks, to guarantee uniform distribution of positioning sequences. Patients included in the study received a number in order (from 1 to 200) that determined the sequence of positioning from the list.

\section{Intervention}

To measure the degree of positioning we used the mini digital protractor BevelBox (Anyi Instrument Co. Ltd., China). The angle sensor was calibrated prior to each measurement.

In the assessment period before intervention, we recorded the following parameters in all patients: positioning degree $\left({ }^{\circ}\right)$; age (years); gender; weight $(\mathrm{kg})$; height $(\mathrm{m})$; admission diagnosis; SAPS II; duration of mechanical ventilation $(\mathrm{h})$ for the time between admission to ICU and intervention; tidal volume $(\mathrm{mL})$; positive end-expiratory pressure (PEEP) (cmH2O); ventilation mode (either pressure-controlled ventilation (PCV) or pressure support ventilation (PSV)); peak airway pressure $\left(\mathrm{P}_{\max }\right)(\mathrm{cmH} 2 \mathrm{O})$; level of inotropic support; dose of propofol and sufentanil for sedation; fluid balance in the last $24 \mathrm{~h}(\mathrm{~mL} / 24 \mathrm{~h})$; and serum albumin $(\mathrm{g} / \mathrm{L})$, hemoglobin $(\mathrm{g} / \mathrm{dL})$, and C-reactive protein (CRP) $(\mathrm{mg} / \mathrm{dL})$ concentrations. Only patients who mantained the hemodynamic stability during the assessment period were eligible for the protocol administration. The first 
backrest position was then adopted according to the randomization sequence. After 3 min to allow for hemodynamic adaptation, heart rate, systolic and diastolic blood pressure, and mean arterial pressure were recorded. The blood pressure was measured in all patients via arterial catheter placed either in the radial or femoral artery. The correct position of an arterial pressure transducer was evaluated after each positioning maneuvre. Simultaneously, $2 \mathrm{~mL}$ of blood were taken via jugular or subclavian central line for assessment of central venous oxygen saturation. The central venous oxygen saturation $(\mathrm{ScvO} 2)$ values were automatically transferred from the blood gas analyzer (Radiometer, ABL 800, Flex, Copenhagen, Denmark) via network cable to the digital patient record system (Metavision Suite, iMD-soft, Tel Aviv, Israel). Then, these parameters were recorded in exactly the same way for the second and third positions. After the study was complete, the patient was returned to their original position. While the study protocol was being enacted, no changes were made to the doses of vasopressor or sedative drugs or the ventilator settings, nor were additional fluids administered.

\section{Statistical methods}

Continuous variables are presented as means and standard deviations (SD) or as median values and interquartile ranges (IQR: q3-q1); categorical variables are presented as absolute numbers and proportions. Normality was verified according to statistical parameters (mean, median, skewness, and kurtosis) and visually by Q-Q Plots. To analyze the impact of $\operatorname{HBE}\left(0^{\circ}, 30^{\circ}\right.$, and $\left.45^{\circ}\right)$ and of the covariables (as listed in Table 1) on the mean arterial pressure (MAP) and on the ScvO2, linear mixed models were used. According to our primary aim, we analyzed the differences in MAP and $\mathrm{ScvO} 2$ between the degrees of HBE without regard for additional covariates. We provided mean values and SD as parameter estimates and adjusted the post-hoc pairwise comparisons by the Tukey-Kramer method. In the further analysis, we calculated different bivariable models, each containing HBE, an additional covariable, and its interaction term. Afterwards a multivariable model was calculated including all variables with a $P$ value $<0.1$ according to the bivariable model. In all mixed models the Kenward-Roger approximation was used, while HBE was used as a repeated effect and the correlation structure between the degrees of HBE was specified as unstructured. The normality of the residuals was tested by means of Q-Q Plots. For graphical illustrations, box plots and scatter plots were used. Both univariable and multivariable logistic regression models were conducted to analyze the risk for a mean arterial pressure $<65 \mathrm{mmHg}$ (MAP $<65 \mathrm{mmHg}$ ) and a central venous oxygen saturation $<70 \%$ ( $\mathrm{ScvO} 2<70 \%$ ), respectively, in the $45^{\circ}$ position, according to the measured variables. The multivariable models were
Table 1 Baseline characteristics of study patients $(n=200)$.

\begin{tabular}{|c|c|}
\hline & $n(\%)$ \\
\hline \multicolumn{2}{|l|}{ Admission diagnosis } \\
\hline Postoperative cancer surgery & $52(26.0)$ \\
\hline Trauma (excluding TBI) & $29(14.5)$ \\
\hline Cardiovascular/cardiogenic shock & $29(14.5)$ \\
\hline Infection/sepsis & $27(13.5)$ \\
\hline Acute respiratory failure & $10(5.0)$ \\
\hline Chronic respiratory failure & $2(1.0)$ \\
\hline Transplantation & $20(10.0)$ \\
\hline CPR (reanimation) & $1(0.5)$ \\
\hline Gastrointestinal & $11(5.5)$ \\
\hline Liver failure & $5(2.5)$ \\
\hline Intoxication & $1(0.5)$ \\
\hline Shock/hemorrhage & $4(2.0)$ \\
\hline Neurological/stroke & $5(2.5)$ \\
\hline Others & $4(2.0)$ \\
\hline \multicolumn{2}{|l|}{ Sex } \\
\hline Male & $131(65.5)$ \\
\hline Female & $69(34.5)$ \\
\hline \multicolumn{2}{|l|}{ Ventilator mode } \\
\hline Spontaneous PSV & $74(37)$ \\
\hline \multirow[t]{2}{*}{ Controlled PCV } & $126(63)$ \\
\hline & Mean (SD) \\
\hline Age (years) & $60.0(15.9)$ \\
\hline BMI $\left(\mathrm{kg} / \mathrm{m}^{2}\right)$ & $27.3(5.9)$ \\
\hline SAPS II & $39.0(11.8)$ \\
\hline Average backrest elevation $\left(^{\circ}\right)$ & $25.6(6.3)$ \\
\hline Peak pressure $\left(\mathrm{cm} \mathrm{H}_{2} \mathrm{O}\right)$ & $20.0(4.6)$ \\
\hline Fluid balance last $24 \mathrm{~h}(\mathrm{~mL})$ & $620(1102)$ \\
\hline Albumin $(\mathrm{g} / \mathrm{L})$ & $22.5(6.2)$ \\
\hline \multirow[t]{2}{*}{$\mathbf{H b}(\mathrm{g} / \mathrm{dl})$} & $9.5(1.9)$ \\
\hline & Median (IQR) \\
\hline Ventilator hours $(h)$ & $24(55)$ \\
\hline Tidal volume $\mathrm{V}_{\mathrm{t}}(\mathrm{mL})$ & $495(141)$ \\
\hline PEEP $\left(\mathrm{cm} \mathrm{H}_{2} \mathrm{O}\right)$ & $6(4)$ \\
\hline Norepinephrine $(\mu \mathrm{g} / \mathrm{kg} / \mathrm{min})$ & $0.07(0.12)$ \\
\hline Propofol (mg/kg/min) & $0.02(0.03)$ \\
\hline Sufentanil ( $\mu \mathrm{g} / \mathrm{kg} / \mathrm{min})$ & $0.01(0.01)$ \\
\hline CRP $(\mathrm{mg} / \mathrm{L})$ & $92.9(145.8)$ \\
\hline
\end{tabular}

$\mathrm{BMI}$, body mass index; CPR, cardiopulmonary resuscitation; CRP, C-reactive protein; $\mathrm{Hb}$, hemoglobin; Pmin, max, minimum and maximum; $\mathrm{PCV}$, pressurecontrolled ventilation; PEEP, positive end-expiratory pressure; PSV, pressure support ventilation; SAPS II, Simplified Acute Physiology Score; TBI, traumatic brain injury.

built using backward selection according to the likelihood ratio. For all significant covariables, we calculated odds ratios (OR) and corresponding 95\% confidence intervals (95\% CI). All reported $P$ values are two-sided, and a $P$ value of 0.05 is considered the threshold of statistical significance. Since the assessment of the covariables was of purely explorative nature, no adjustment for multiple testing was done. Data entry and calculations were made with 
the software package SPSS 19.0 (IBM, Chicago, IL, USA), and the linear mixed model analyses were undertaken using the SAS 9.2 procedure PROC MIXED (SAS Institute, Cary, NC, USA).

\section{Results}

In total, 202 patients were recruited but on two occasions the study protocol was abandoned because of severe hypotension requiring volume and inotropic resuscitation. The baseline characteristics of all patients are shown in Table 1.

There were significant differences between the three HBE positions for MAP $(P<0.001)$ as well as for $\mathrm{ScvO} 2$ $(P<0.001$, Table 2$)$. Only HBE from $0^{\circ}$ to $30^{\circ}$ was not associated with a significant decrease in $\mathrm{ScvO}$ 2. For MAP as the dependent variable, in each of the bivariable models with the fixed factor HBE and an additional covariate, HBE stayed significant in all models and the covariates SAPS II, norepinephrine as well as its interaction with HBE (norepinephrine*HBE), ventilation mode, sufentanil, and propofol were found to be significant (Figures 1 and 2). In the subsequent multivariable model the variables $\mathrm{HBE}$, norepinephrine"HBE, and ventilation mode had significant effects (Table 3 ).

Taking ScvO2 as the dependent variable, HBE remained significant in all bivariable models and the covariates time of ventilation and its interaction with HBE and norepinephrine were also significant. In the multivariable model a significant effect was found for $\mathrm{HBE}$, time of ventilation, time of ventilation and its interaction with $\mathrm{HBE}$, norepinephrine, and ventilation mode (Table 4).

To calculate the risk of MAP falling below $65 \mathrm{mmHg}$ in the $45^{\circ}$ position, the group of patients who maintained MAP above this threshold was compared with those who did not (MAP $<65 \mathrm{mmHg}$ group). In the univariable comparison between both groups we found significant differences in: mean PEEP level, mean $P_{\max }$, mean dose of norepinephrine, mean initial backrest position, and ventilation mode (Table 5). In the univariable comparison of groups with $\mathrm{ScvO} 2<70 \%$ and $\mathrm{ScvO} 2>70 \%$ in the $45^{\circ}$ position, none of the variables showed significant differences.

In the multivariable logistic regression model, patients in the semirecumbent position had an OR for MAP
$<65 \mathrm{mmHg}$ of 1.03 by raising the dose of norepinephrine (per $0.01 \mu \mathrm{g} / \mathrm{kg} / \mathrm{min}$ increase, 95\% CI 1.01 to $1.06, P=0.023)$, of 1.13 by raising the level of PEEP (per $1 \mathrm{cmH}_{2} \mathrm{O}$ increase, 95\% CI 1.02 to $1.26, P=$ 0.0019 ) and of 2.33 if they were ventilated in pressurecontrolled compared with pressure support mode (95\% CI 1.16 to $4.69, P=0.017$ ). Moreover, patients with higher backrest elevation before the intervention were at a significantly lower risk of MAP $<65 \mathrm{mmHg}$ in the $45^{\circ}$ position (OR $0.93,95 \%$ CI 0.88 to $0.98, P=0.005$ ) (Table 6).

\section{Discussion}

This is the first prospective randomized self-controlled study evaluating the influence of upright positioning on hemodynamic stability. We found that increasing the angle of $\mathrm{HBE}$ to $30^{\circ}$ and $45^{\circ}$ is clearly associated with significant decreases in MAP when patients are mechanically ventilated. Moreover, the semirecumbent $45^{\circ}$ position appears to cause significant falls in ScvO2. This suggests that the recommended semi-upright $\left(30^{\circ}\right)$ and upright $\left(45^{\circ}\right)$ positions may not be feasible in some mechanically ventilated patients.

Increasing the elevation of the head of the bed induces a gravitational transfer of blood from the upper body and central circulatory compartment towards the abdomen and lower limbs. This pooling of blood in the extremities reduces systemic venous return to the right heart and reduces cardiac output. Upright positioning may be responsible for lower mean circulatory pressure in ventilated patients, even if current evidence is lacking. Giving additional fluid boluses to increase circulating volume or increasing vasopressor support can reverse all these hemodynamic changes [11-14].

In our study upright body positioning at $45^{\circ}$ was associated with sustained drop of MAP $<65 \mathrm{mmHg}$ in 72 (36\%) patients. In addition, $\mathrm{ScvO} 2$ fell to below $70 \%$ in 62 (31\%) patients. A MAP $>65 \mathrm{mmHg}$ and $\mathrm{ScrO} 2>70 \%$ are widely accepted and recommended hemodynamic parameters for adequate tissue perfusion and oxygenation in critically ill patients, targets that were not achieved by approximately one-third of our patients in the $45^{\circ}$ position [15].

Our results showed significantly higher values for $\mathrm{MAP}$ and $\mathrm{ScvO} 2$ in the supine position. This may reflect the short-term effect of an improved circulation profile

Table 2 Influence of HBE on MAP and ScvO2.

\begin{tabular}{|c|c|c|c|c|}
\hline & \multicolumn{3}{|c|}{ HBE (mean (SD)) } & \multirow{2}{*}{$\begin{array}{l}P \text { values }^{\mathrm{a}} \\
\text { Global }\left(0^{\circ} \text { vs. } 30^{\circ} ; 0^{\circ} \text { vs. } 45^{\circ} ; 30^{\circ} \text { vs. } 45^{\circ}\right.\end{array}$} \\
\hline & $\overline{0^{\circ}}$ & $30^{\circ}$ & $45^{\circ}$ & \\
\hline MAP $(\mathrm{mmHg})$ & $83.8(14.5)$ & $75.1(13.1)$ & $71.1(15.2)$ & $<0.001(<0.001 ;<0.001 ;<0.001)$ \\
\hline ScvO2 (\%) & $76.1(8.0)$ & $75.6(8.2)$ & $74.3(9.0)$ & $<0.001(0.26 ;<0.001 ; 0.001)$ \\
\hline
\end{tabular}

$\mathrm{HBE}$, head of bed elevation; MAP, mean arterial pressure; ScvO2, central venous oxygen saturation.

${ }^{a}$ According to Proc Mixed with Tukey-Kramer adjusted $P$ values for pairwise comparisons. 


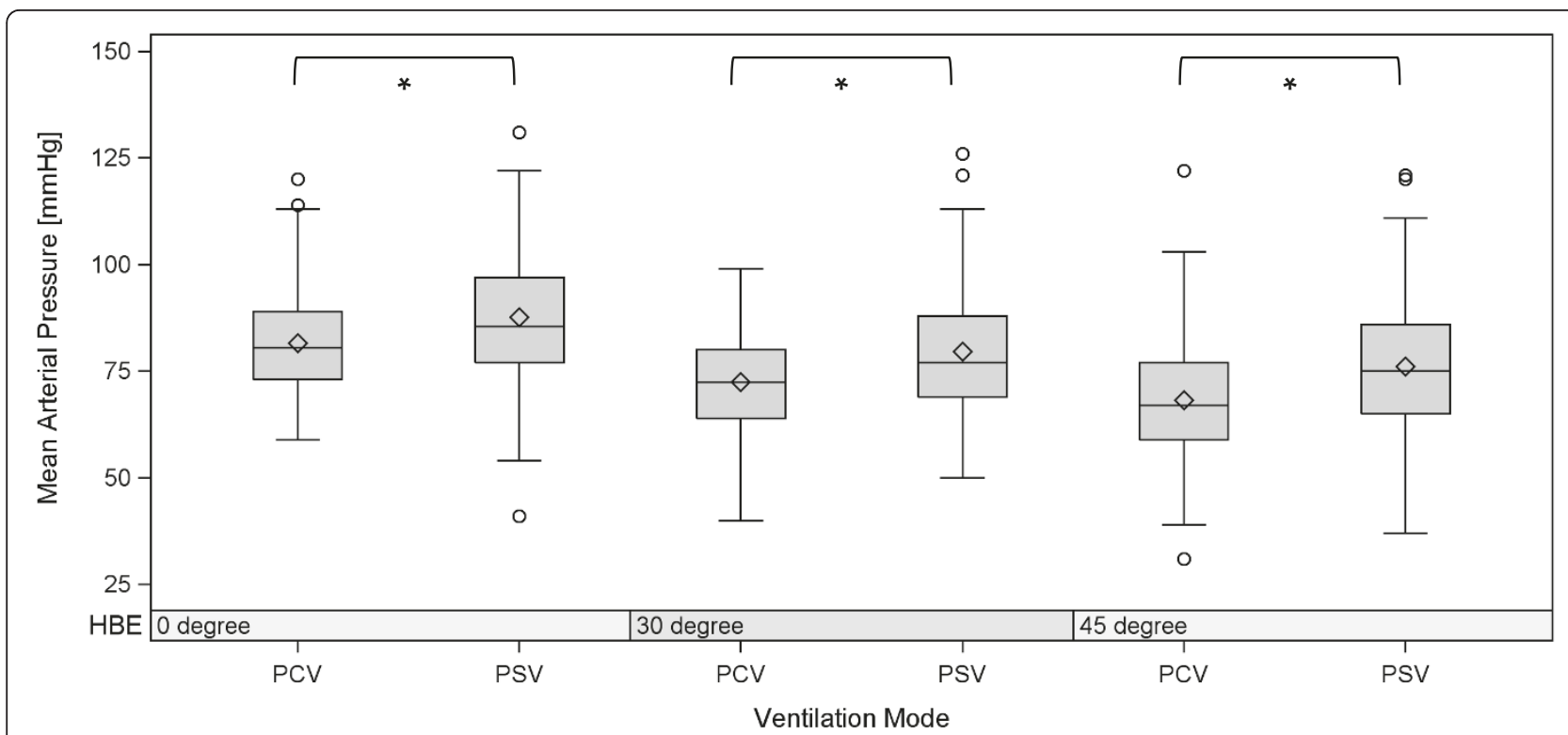

Figure 1 Effect of PCV vs. PSV on mean arterial pressure with significant effect in all three degrees of backrest positioning, $P<0.001$ ${ }^{*} P<0.001$ : influence of ventilation mode on mean arterial pressure according to the linear mixed model. PCV: pressure controlled ventilation; PSV: pressure support ventilation.

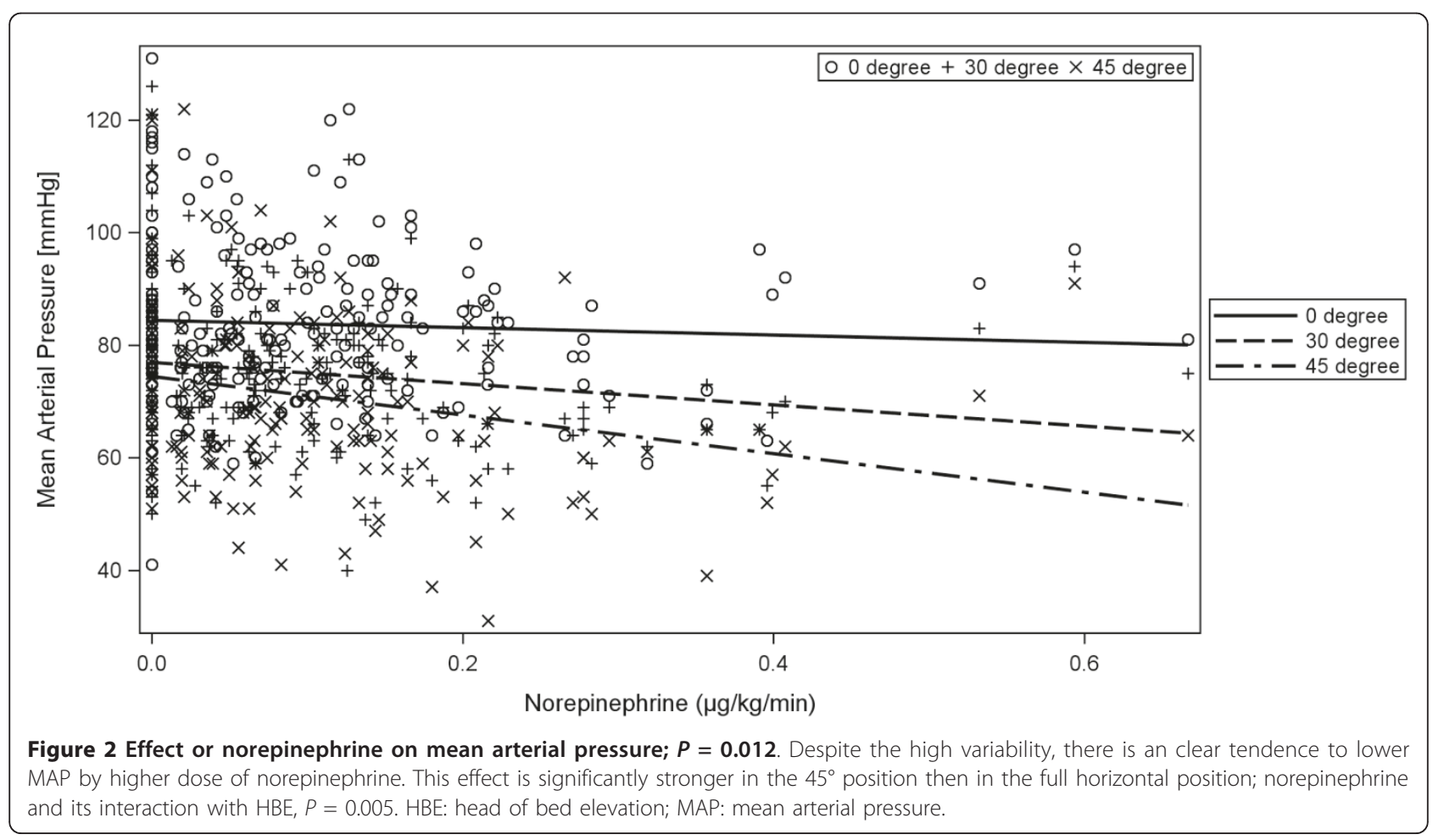

with higher systemic venous return, higher cardiac output, and, as a consequence, improved oxygen delivery. However, the supine position is clearly associated with increased incidence of ventilator-associated pneumonia, lung de-recruitment, and hypoxemia $[16,17]$. Any short-term positive effect on MAP and $\mathrm{ScvO} 2$ in the supine position is likely to be outweighed by respiratory complications in the longer term.

Our results suggest that critically ill patients in early phase after admission who require PCV and inotropic 
Table 3 Variables influencing MAP.

\begin{tabular}{|c|c|c|}
\hline & $\begin{array}{l}\text { Bivariable } \\
\text { model }^{\mathrm{a}} \\
P \text { value }\end{array}$ & $\begin{array}{l}\text { Multivariable } \\
\text { model }^{\mathbf{b}} \\
P \text { value }\end{array}$ \\
\hline HBE & $<0.001$ & $<0.001$ \\
\hline SAPS II & 0.023 & n.s. \\
\hline Norepinephrine ( $\mu \mathrm{g} / \mathrm{kg} / \mathrm{min})$ & 0.012 & n.s. \\
\hline Norepinephrine*HBE & 0.005 & 0.005 \\
\hline Ventilation mode & $<0.001$ & $<0.001$ \\
\hline Sedation sufentanil $(\mu \mathrm{g} / \mathrm{kg} / \mathrm{min})$ & 0.027 & n.s. \\
\hline Sedation propofol (mg/kg/min) & 0.034 & n.s. \\
\hline
\end{tabular}

${ }^{a}$ All bivariable models include HBE as a factor.

${ }^{\mathrm{b}}$ The multivariable model contains all variables with a $P$ value $<0.1$. HBE, head of bed elevation; n.s., not significant; SAPS II, Simplified Acute Physiology Score.

support are at high risk of a significant decrease in ScvO2 by increasing backrest position. Patients who required long-term ventilation showed significantly higher ScvO2 levels at the time of the study. They may have been in the recovery phase, with positive cumulative fluid balance and more cardiovascular reserve, lower oxygen demand, and less invasive mechanical ventilation than patients in the acute phase.

The dose of norepinephrine, level of PEEP, the PCV mode, and the angle of backrest elevation before the head of the bed was elevated can help identify patients at risk of hypotension (MAP $<65 \mathrm{mmHg}$ ) when they are moved into the $45^{\circ}$ position. The hemodynamic effect of PEEP on MAP is well known. Increased PEEP levels raise intrathoracic pressure, decrease right and left ventricular afterload and contractility leading to lower systemic blood pressure, especially in hypovolemic patients [18-20]. We found that raising the level of PEEP by $1 \mathrm{~cm} \mathrm{H}_{2} \mathrm{O}$ creates a relative risk of hypotension (MAP $<65 \mathrm{mmHg}$ ) of 1.13 in the $45^{\circ}$ position, but also that increasing norepinephrine dose by $0.01 \mu \mathrm{g} / \mathrm{kg} / \mathrm{min}$ is associated with a relative hypotension risk of 1.03. Increasing dose of norepinephrine reduces unstressed volume and vascular responsiveness. The greatest risk was $\mathrm{PCV}$, which was associated with a relative

Table 4 Variables influencing ScvO2.

\begin{tabular}{cll}
\hline & $\begin{array}{l}\text { Bivariable } \\
\text { model }^{\mathbf{a}} \boldsymbol{P} \\
\text { value }\end{array}$ & $\begin{array}{l}\text { Multivariable }_{\text {model }^{\mathbf{b}} \boldsymbol{P}} \\
\text { value }^{2}\end{array}$ \\
\hline HBE & $<0.001$ & 0.003 \\
\hline Time of ventilation (h) & n.s. & 0.036 \\
Time of ventilation*HBE & 0.035 & 0.035 \\
Norepinephrine $(\boldsymbol{\mu g} / \mathbf{k g} / \mathrm{min})$ & 0.006 & 0.009 \\
Ventilation mode & n.s. & 0.039 \\
\hline
\end{tabular}

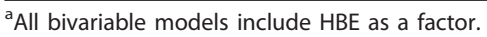

${ }^{\mathrm{b}}$ The multivariable model contains all variables with a $P$ value $<0.1$.

$\mathrm{HBE}$, head of bed elevation; n.s., not significant; ScvO2, central venous oxygen saturation. risk of 2.33 for MAP $<65 \mathrm{mmHg}$ in the semirecumbent position. There are several reasons why the spontaneous (PSV) ventilator mode may be less deleterious on MAP during backrest elevation. Spontaneous inspiration with diaphragmatic contraction decreases intrathoracic pressure and hence systemic venous return to the heart is increased [21]. Furthermore, there is clear evidence that spontaneous breathing improves oxygenation and is associated with better systemic, hepatic, and intestinal blood flows [22,23].

Van Nieuwenhoven and colleagues have evaluated the feasibility of adopting the semirecumbent position in the daily routine for ventilated critically ill patients. They found that the targeted upright position of $45^{\circ}$ was not attained for $85 \%$ of the study time in the semirecumbent group. Average elevations in the study group were $28.1^{\circ}$ and $22.6^{\circ}$ at days 1 and 7, respectively [24]. We measured the level of backrest elevation before starting intervention. Our findings support the previous published data with mean average backrest elevation of $25.6^{\circ}$. Moreover, the results showed that patients who developed a MAP $<65 \mathrm{mmHg}$ in $45^{\circ}$ position had been nursed at significantly lower angles of backrest elevation before the intervention when compared with those whose MAP was maintained above $65 \mathrm{mmHg}\left(23.6^{\circ}\right.$ versus $\left.26.6^{\circ}\right)$. This suggests that patients at high risk of hypotension in the semirecumbent position are those who are routinely nursed below the recommended $30^{\circ}$ to $45^{\circ}$ of backrest elevation.

According to current published data, raising the head of the bed to $30^{\circ}$ and $45^{\circ}$ significantly increases the peak interface pressure between the skin at the sacral area and support surfaces in healthy volunteers, and in this context decubitus ulcers still remain a concern [25]. Positioning patients in the semirecumbent position is also associated with significant changes in intra-abdominal pressure [26-28]. We did not measure these variables in the present study. Other potential limitations are that our study was conducted in one center, a surgical ICU with a higher proportion of postoperative patients undergoing relatively short durations of PCV ventilation before the study. Our results may therefore be more generalizable for patients in the early acute phase after admission to the ICU rather than long-term ventilated ICU patients. Furthermore, due to the relatively low proportion of patients with acute respiratory failure, the strong effect of pressure controlled ventilation could have been caused by vast intrathoracic transmission of airway pressure. Therefore our results may have potential limitation if applied to patients with significantly reduced lung compliance. Finally, we only evaluated the hemodynamic response to HBE over $3 \mathrm{~min}$. We found that most hemodynamic changes occurred within $30 \mathrm{~s}$ to $90 \mathrm{~s}$, not dissimilar to the 
Table 5 Univariate logistic regressions on high-risk (MAP <65) versus low-risk (MAP >65) patients in the $45^{\circ}$ position.

\begin{tabular}{|c|c|c|c|c|c|}
\hline & & MAP $>65 \mathrm{mmHg}(n=128)$ Mean (SD) & MAP $<65 \mathrm{mmHg}(n=72)$ Mean (SD) & OR & $P$ value \\
\hline \multicolumn{2}{|l|}{ Age (years) } & $59.8(16.0)$ & $60.5(15.7)$ & 1.00 & 0.77 \\
\hline \multicolumn{2}{|l|}{ BMI } & $27.1(5.0)$ & $27.7(7.2)$ & 1.02 & 0.52 \\
\hline \multicolumn{2}{|l|}{ SAPS II } & $37.9(11.1)$ & $40.9(12.6)$ & 1.02 & 0.09 \\
\hline \multicolumn{2}{|c|}{$\begin{array}{l}\text { Measured backrest elevation before } \\
\text { intervention }\left(^{\circ}\right)\end{array}$} & $26.6(6.2)$ & $23.6(6.0)$ & 0.92 & 0.002 \\
\hline \multicolumn{2}{|c|}{ Peak pressure $\left(\mathrm{cm} \mathrm{H}_{2} \mathrm{O}\right)$} & $19.3(4.6)$ & $21.3(4.4)$ & 1.10 & 0.005 \\
\hline \multicolumn{2}{|c|}{ Fluid balance last $24 \mathrm{~h}(\mathrm{~mL})$} & $565(1105)$ & $718(1097)$ & 1.00 & 0.35 \\
\hline \multicolumn{2}{|l|}{ Albumin $(\mathrm{g} / \mathrm{L})$} & $22.6(6.3)$ & $22.3(6.2)$ & 0.99 & 0.76 \\
\hline \multicolumn{2}{|l|}{$\mathbf{H b}(\mathrm{g} / \mathrm{dL})$} & $9.6(2.0)$ & $9.4(1.8)$ & 0.92 & 0.30 \\
\hline \multirow{2}{*}{\multicolumn{2}{|c|}{ CRP $(\mathrm{mg} / \mathrm{L})$}} & $115.2(92.1)$ & $116.6(97.3)$ & 1.00 & 0.92 \\
\hline & & Median (IQR) & Median (IQR) & & \\
\hline \multicolumn{2}{|c|}{ Ventilation hours $(h)$} & $24(55)$ & $28(55)$ & 1.00 & 0.45 \\
\hline \multicolumn{2}{|l|}{ Tidal volume $(\mathrm{mL})$} & $490(147)$ & $502.5(140)$ & 1.00 & 0.92 \\
\hline \multicolumn{2}{|l|}{ PEEP $\left(\mathrm{cm} \mathrm{H}_{2} \mathrm{O}\right)$} & $6(3)$ & $7.5(5)$ & 1.13 & 0.013 \\
\hline \multicolumn{2}{|c|}{ Norepinephrine $(\mu \mathrm{g} / \mathrm{kg} / \mathrm{min})$} & $0.06(0.12)$ & $0.09(0.16)$ & $1.04^{\mathrm{a}}$ & 0.005 \\
\hline \multicolumn{2}{|c|}{ Propofol (mg/kg/min) } & $0.02(0.03)$ & $0.02(0.02)$ & $1.07^{\mathrm{a}}$ & 0.44 \\
\hline \multicolumn{2}{|c|}{ Sufentanil $(\mu \mathrm{g} / \mathrm{kg} / \mathrm{min})$} & $0.01(0.01)$ & $0.01(0.01)$ & $1.00^{\mathrm{b}}$ & 0.99 \\
\hline \multicolumn{2}{|c|}{ Epinephrine $(\mu \mathrm{g} / \mathrm{kg} / \mathrm{min})$} & $0.00(0.00)$ & $0.00(0.00)$ & $1.02^{\mathrm{b}}$ & 0.33 \\
\hline \multicolumn{2}{|c|}{ Dobutamin ( $\mu \mathrm{g} / \mathrm{kg} / \mathrm{min})$} & $0.00(0.00)$ & $0.00(0.00)$ & 1.28 & 0.37 \\
\hline \multirow{2}{*}{\multicolumn{2}{|c|}{ CRP $(\mathrm{mg} / \mathrm{L})$}} & $103.5(145.8)$ & $88.4(154.4)$ & 1.00 & 0.92 \\
\hline & & Cases (\%) & Cases (\%) & & \\
\hline \multirow[t]{2}{*}{ Ventilation mode } & Spontaneous (PSV) & $57(44.5 \%)$ & $17(23.6 \%)$ & 1.61 & 0.004 \\
\hline & Controlled (PCV) & $71(55.5 \%)$ & 55 (76.4\%) & & \\
\hline
\end{tabular}

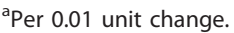

${ }^{\mathrm{b}}$ Per 0.001 unit change.

BMI, body mass index; CRP, C-reactive protein; Hb, hemoglobin; IQR, interquartile range; MAP, mean arterial pressure; OR, odds ratio; PCV, pressure-controlled ventilation; PEEP, positive end-expiratory pressure; PSV, pressure support ventilation; SAPS II, Simplified Acute Physiology Score; SD, standard deviation.

time taken for cardiac stroke volume to change after passive leg raising $[29,30]$. We believe that within the constraints of our protocol we detected all acute hemodynamic changes associated with altering the angle of the backrest, but cannot determine whether these changes would be maintained over time and what the longer-term consequences of these changes are.

Based on current evidence, the semirecumbent position clearly prevents VAP when compared to full horizontal position. Nevertheless, it is still unclear whether the $45^{\circ}$ degree backrest elevation as originally reported by the

Table 6 Multivariate logistic regression model on high-risk patients (MAP <65) in the $45^{\circ}$ position.

\begin{tabular}{|c|c|c|}
\hline & OR $(95 \% \mathrm{CI})^{\mathrm{a}}$ & $P$ value \\
\hline Norepinephrine $(\mu \mathrm{g} / \mathrm{kg} / \mathrm{min})$ & $1.03^{b}(1.01,1.06)$ & 0.023 \\
\hline PEEP & $1.13(1.02,1.26)$ & 0.019 \\
\hline Backrest elevation $\left({ }^{\circ}\right)$ & $0.93(0.88,0.98)$ & 0.005 \\
\hline Ventilation mode ${ }^{c}$ & $2.33(1.16,4.69)$ & 0.017 \\
\hline
\end{tabular}

${ }^{\mathrm{a}}$ Odds ratio and $95 \%$ confidence interval.

${ }^{b}$ Per 0.01 unit change.

'Spontaneous (0), controlled (1).

PEEP, positive end-expiratory pressure.
Drakulovic's study is feasible, and whether lower inclination of head of bed could still be beneficial. The future studies may systematically address safety of the HBE and identify the safest, most effective head of bed orientation for patients on invasive mechanical ventilation.

\section{Conclusions}

Adopting the $45^{\circ}$ semirecumbent position is strongly associated with decreases in MAP and $\mathrm{ScvO} 2$ in mechanically ventilated patients. Patients who are sedated, undergoing pressure-controlled ventilation, with higher SAPS II scores, receiving elevated levels of PEEP or higher dose of norepinephrine are at greatest risk of hypotension. They may need positioning at $20^{\circ}$ to $30^{\circ}$ to overcome the negative influences of backrest elevation on hemodynamic stability, especially in the early phase of critical illness.

\section{Key messages}

- Elevating the head of the bed to $45^{\circ}$ is associated with significant decreases in MAP and $\mathrm{ScvO} 2$ in mechanically ventilated patients.

- Pressure-controlled ventilation, increasing SAPS II score, sedation, high catecholamine, and PEEP 
requirements are independent risk factors for hypotension after backrest elevation.

- Patients at risk may need positioning at $20^{\circ}$ to $30^{\circ}$ to overcome the negative effects of $\mathrm{HBE}$, especially in the early phase of ICU admission.

\section{Abbreviations}

ARDS: acute respiratory distress syndrome; BMI: body mass index; $\mathrm{Cl}$ : confidence interval; CPR: cardiopulmonary resuscitation; CRP: C-reactive protein; HBE: head of bed elevation; ICU: intensive care unit; MAP: mean arterial pressure; OR: odds ratio; PCV: pressure controlled ventilation; PEEP positive end expiratory pressure; PSV: pressure support ventilation, SAPS II: simplified acute physiology score; ScvO2: central venous oxygen saturation; VAP: ventilator-associated pneumonia.

\section{Competing interests}

The authors declare that they have no competing interests.

\section{Authors' contributions}

TB was responsible for the study design. FS and IG were responsible for administering the protocol. FZ, FS, IG, and TB performed the data analysis and were responsible for interpretation of data. IG, FZ, and TB drafted the manuscript. MC, BMG, and HJS critically reviewed the manuscript. All authors have given final approval of this version of the manuscript.

\section{Authors' details}

${ }^{1}$ Department of Surgery, University Medical Centre Regensburg, Franz-JosefStrauss-Allee 11, D-93053 Regensburg, Germany. ²University of Regensburg, Universitätstrasse 31, D-93053 Regensburg, Germany. ${ }^{3}$ Centre for Clinical Studies, University Medical Centre Regensburg, Franz-Josef-Strauss-Allee 11, D-93053 Regensburg, Germany. ${ }^{4}$ Department of Anaesthesiology, University Medical Centre Regensburg, Franz-Josef-Strauss-Allee 11, D-93053 Regensburg, Germany.

Received: 9 September 2012 Revised: 7 February 2013

Accepted: 26 April 2013 Published: 26 April 2013

\section{References}

1. Ibrahim EH, Tracy L, Hill C, Fraser VJ, Kollef MH: The occurrence of ventilator-associated pneumonia in a community hospital: risk factors and clinical outcomes. Chest 2001, 120:55-61.

2. Rello J, Soñora $R$, Jubert $P$, Artigas $A$, Rué M, Vallés J: Pneumonia in intubated patients: role of respiratory airway care. Am J Respir Crit Care Med 1996, 154:111-115.

3. Joseph NM, Sistla S, Dutta TK, Badhe AS, Parija SC: Ventilator-associated pneumonia: a review. Eur J Intern Med 2010, 21:360-368.

4. Nseir S, Zerimech F, Fournier C, Lubret R, Ramon P, Durocher A, Balduyck M: Continuous control of tracheal cuff pressure and microaspiration of gastric contents in critically ill patients. Am J Respir Crit Care Med 2011, 184:1041-1047.

5. Kollef MH: Ventilator-associated pneumonia. A multivariate analysis. JAMA 1993, 270:1965-1970.

6. Torres A, Serra-Batlles J, Ros E, Piera C, Puig de la Bellacasa J, Cobos A Lomeña F, Rodríguez-Roisin R: Pulmonary aspiration of gastric contents in patients receiving mechanical ventilation: the effect of body position. Ann Intern Med 1992, 116:540-543.

7. Orozco-Levi M, Torres A, Ferrer M, Piera C, el-Ebiary M, de la Bellacasa JP, Rodriguez-Roisin R: Semirecumbent position protects from pulmonary aspiration but not completely from gastroesophageal reflux in mechanically ventilated patients. Am J Respir Crit Care Med 1995 152:1387-1390.

8. Drakulovic MB, Torres A, Bauer T, Nicolas JM, Nogué S, Ferrer M: Supine body position as a risk factor for nosocomial pneumonia in mechanically ventilated patients: a randomised trial. Lancet 1999, 354:1851-1858.

9. Niël-Weise BS, Gastmeier P, Kola A, Vonberg RP, Wille JC, van den Broek PJ: Bed Head Elevation Study Group. An evidence-based recommendation on bed head elevation for mechanically ventilated patients. Crit Care 2011, 15:R111.

10. Le Gall JR, Lemeshow S, Saulnier F: A new Simplified Acute Physiology Score (SAPS II) based on a European/North American multicenter study. JAMA 1993, 270:2957-2963.

11. Bein T: Positioning in prophylaxis or therapy of pulmonary disorders, S2e-Guideline of the German Society of Anaesthesiology and Intensive Care Medicine. Anästh Intensivmed 2008, 49:S1-S24.

12. Hoste EA, Roosens CD, Bracke S, Decruyenaere JM, Benoit DD, Vandewoude KH, Colardyn FA: Acute effects of upright position on gas exchange in patients with acute respiratory distress syndrome. $J$ Intensive Care Med 2005, , Suppl 1: 43-49.

13. Monnet $X$, Teboul JL: Passive leg raising. Intensive Care Med 2008, 34:659-663.

14. Hamzaoui O, Georger JF, Monet X, Ksouri H, Maizel J, Richard C, Teboul JL: Early administration of norepinephrine increases cardiac preload and cardiac output in septic patients with life-threatening hypotension. Crit Care 2010, 14:R142.

15. Delinger RP, Levy MM, Carlet JM, Bion J, Parker MM, Jaeschke R, Reinhart K, Angus DC, Brun-Buisson C, Beale R, Calandra T, Dhainaut JF, Gerlach H, Harvey M, Marini JJ, Marshall J, Ranieri M, Ramsay G, Sevransky J, Thompson BT, Townsend S, Vender JS, Zimmerman JL, Vincent JL, International Surviving Sepsis Campaign Guidelines Committee; American Association of Critical-Care Nurses; American College of Chest Physicians; American College of Emergency Physicians; Canadian Critical Care Society; European Society of Clinical Microbiology and Infectious Diseases, et al: Surviving Sepsis Campaign: International Guidelines for management of severe sepsis and septic shock. Crit Care Med 2008, 36:296-327.

16. Robak O, Schellongowski P, Bojic A, Laczika K, Locker GJ, Staudinger T: Short-term effects of combining upright and prone positions in patients with ARDS: a prospective randomized study. Crit Care 2011, 15:R230.

17. Richard JC, Maggiore SM, Mancebo J, Lemaire F, Jonson B, Brochard L: Effects of vertical positioning on gas exchange and lung volumes in acute respiratory distress syndrome. Intensive Care Med 2006, 32:1623-1626.

18. Rivers EP, Ander DS, Powell D: Central venous oxygen saturation monitoring in critically ill patient. Curr Opin Crit Care 2001, 7:204-11.

19. Miranda DR, Klompe L, Cademartiri F, Haitsma JJ, Palumbo A, Takenberg JJ, Lachmann B, Bogers AJ, Gommers D: The effect of open lung ventilation on right ventricular and left ventricular function in lung-lavaged pigs. Crit Care 2006, 10:R86.

20. Gernoth C, Wagner G, Pelosi P, Luecke T: Respiratory and haemodynamic changes during decremental open lung positive end-expiratory pressure titration in patients with acute respiratory distress syndrome. Crit Care 2009, 13:R59.

21. Pinsky MR: Cardiovascular issues in respiratory care. Chest 2005, , Suppl 2: 592-597.

22. Wrigge $H$, Zinserling J, Neumann P, Defosse J, Magnusson A, Putensen C, Hedenstiema G: Spontaneous breathing improves lung aeration in oleic acid induced lung injury. Anesthesiology 2003, 99:376-84.

23. Hering $R$, Viehöfer $A$, Zinserling J, Wrigge $H$, Kreyer $S$, Berg A, Minor $T$, Putensen C: Effects of spontaneous breathing during airway pressure release ventilation on intestinal blood flow in experimental lung injury. Anesthesiology 2003, 99:1137-1144.

24. van Nieuwenhoven CA, Vandenbroucke-Grauls C, van Tiel FH, Joore HC, van Schijndel RJ, van der Tweel I, Ramsay G, Bonten MJ: Feasibility and effects of the semirecumbent position to prevent ventilator-associated pneumonia: a randomized study. Crit Care Med 2006, 34:396-402.

25. Peterson M, Schwab W, McCutcheon K, van Oostrom JH, Gravenstein N, Caruso L: Effects of elevating the head of bed on interface pressure in volunteers. Crit Care Med 2008, 36:3038-3042.

26. Ejike JC, Kadry J, Bahjri K, Mathur M: Semi-recumbent position and body mass percentiles: effects on intra-abdominal pressure measurements in critically ill children. Intensive Care Med 2010, 36:329-335

27. McBeth PB, Zygun DA, Widder S, Cheatham M, Zengerink I, Glowa J, Kirkpatrick AW: Effect of patient positioning on intra-abdominal pressure monitoring. Am J Surg 2007, 193:644-647.

28. Yi M, Leng $Y$, Bai $Y$, Yao G, Zhu X: The evaluation of the effect of body positioning on itra-abdominal pressure measurement and the effect of intra-abdominal pressure at different body positioning on organ 
function and prognosis in critically ill patients. J Crit Care 2012, , Suppl 2: 222

29. Biais M, Vidil L, Sarrabay P, Cottenceau V, Revel P, Sztark F: Changes in stroke volume induced by passive leg raising in spontaneously breathing patients: comparison between echocardiography and Vigileo TM/FloTracTM device. Crit Care 2009, 13:R195.

30. Maizel J, Airapetian N, Lorne E, Tribouilloy C, Massy Z, Slama M: Diagnosis of central hypovolemia by using passive leg raising. Intensive Care Med 2007, 33:1133-1138.

doi:10.1186/cc12694

Cite this article as: Göcze et al:: The effects of the semirecumbent position on hemodynamic status in patients on invasive mechanical ventilation: prospective randomized multivariable analysis. Critical Care 2013 17:R80

Submit your next manuscript to BioMed Central and take full advantage of:

- Convenient online submission

- Thorough peer review

- No space constraints or color figure charges

- Immediate publication on acceptance

- Inclusion in PubMed, CAS, Scopus and Google Scholar

- Research which is freely available for redistribution

Submit your manuscript at www.biomedcentral.com/submit 